\title{
Faktor-Faktor Yang Mempengaruhi Manajemen Laba (Pada Perusahaan Sub Sektor Properti dan Real Estate yang terdaftar di BEI pada tahun 2016-2018)
}

\author{
Dirvi Surya Abbas ${ }^{(1)}$ \\ Universitas Muhammadiyah Tangerang \\ abbas.dirvi@gmail.com \\ Ali Kusuma Wardhana ${ }^{(2)}$ \\ Universitas Muhammadiyah Tangerang \\ Alikusuma0009@gmail.com \\ Ahmad Saefudin ${ }^{(3)}$ \\ Universitas Muhammadiyah Tangerang
}

\begin{abstract}
This study aims to determine whether the information Return on Equity, Earning Per Share, Debt to Equity, Price Earning Ratio and Net Profit Margin is used in giving signals to investors about the risk of a Profit Management. Return on Equity is measured by comparing net income after tax with total equity, then Earning Per Share is measured by comparing Net Profit After Tax with the number of shares outstanding, then Debt to Equity is measured by comparing the total debt with total equity, then Price Earning Ratio is measured by comparing the price of shares outstanding with earnings per share and net profit margin measured by comparing net income with sales. This study uses a sample of companies in the Property and Real Estate sector during 2016-2018 using a purposive sampling method. The data used is obtained from annual reports that are listed on the Indonesia Stock Exchange. There were 15 companies during 2016-2018 that met the criteria. The analytical method used is multiple regression analysis with the help of Eviews version 9.0.

The results of this study indicate that partially Return on Equity, with a $t$ value of -3.33744 with a significance value of $0.0017<0.05$. And Earning Per Share, with a value of $t$-statistic of 1.740 with a significance value of $0,0897>0.05$ means positive but not significant effect on Profit Management, while Debt to Equity $t$-value of 0.660 with a significance level of 0.5129> 0.05 means positive but not significant effect on Profit Management. Then the Debt to Equity t-value of -0.050 with a significance level of 0.9598>0.05 means that it has a negative but not significant effect on earnings management. Net Profit Margin Debt to Equity, the $t$-statistic value of -1.999 with a significance level of 0.0526>0.05 means that it has a negative but not significant effect on earnings management.
\end{abstract}

Keywords: Return on Equity, Earning Per Share, Debt to Equity, Price Earning Ratio Net Profit Margin and Profit Management 


\begin{abstract}
ABSTRAK
Penelitian ini bertujuan untuk mengetahui apakah informasi Return on Equity, Earning Per Share, Debt to Equity, Price Earning Ratio dan Net Profit Margin digunakan dalam memberikan sinyal kepada investor atas risiko suatu Manajemen Laba. Return on Equity diukur dengan membandingkan antara laba bersih setelah pajak dengan total ekuitas, lalu Earning Per Share diukur dengan membandingkan antara Laba Bersih Setelah Pajak dengan Jumlah Lembar Saham yang beredar, lalu Debt to Equity diukur dengan membandingkan antara total hutang dengan total ekuitas, lalu Price Earning Ratio diukur dengan membandingkan antara Harga Saham yang beredar dengan Laba Per Lembar Saham dan Net Profit Margin diukur dengan membandingkan antara Laba bersih dengan penjualan.
\end{abstract}

Penelitian ini menggunakan sampel perusahaan sektor Property dan Real Estate selama tahun 2016-2018 dengan menggunakan metode purposive sampling. Data yang digunakan diperoleh dari laporan tahunan yang terdaftar di Bursa Efek Indonesia. Ada 15 perusahaan selama tahun 2016-2018 yang memenuhi kriteria. Metode analisis yang digunakan adalah analisis regresi berganda dengan bantuan Eviews versi 9.0.

Hasil penelitian ini menunjukan bahwa secara parsial Return on Equity, dengan nilai $t$ statistic sebesar $-3,3744$ dengan nilai signifikansi sebesar $0,0017<0,05$.dan Earning Per Share, dengan nilai nilai t statistic sebesar 1,740 dengan nilai signifikansi sebesar 0,0897 >0,05 artinya berpengaruh positif namun tidak signifikan terhadap Manajemen Laba, sementara Debt to Equity nilai nilai t statistic sebesar 0,660 dengan tingkat signifikansi sebesar 0,5129>0,05 artinya berpengaruh positif namun tidak signifikan terhadap Manajemen Laba. Lalu Debt to Equity nilai t statistic sebesar -0,050 dengan tingkat signifikansi sebesar 0,9598 >0,05 artinya berpengaruh negatif namun tidak signifikan terhadap Manajemen Laba. Net Profit Margin Debt to Equity nilai t statistic sebesar -1,999 dengan tingkat signifikansi sebesar 0,0526>0,05 artinya berpengaruh negatif namun tidak signifikan terhadap Manajemen Laba.

Kata Kunci : Return on Equity, Earning Per Share, Debt to Equity, Price Earning Ratio Net Profit Margin dan Manajemen Laba

\title{
PENDAHULUAN
}

Bisnis properti dan real estate adalah bisnis yang dikenal memiliki karakteristik cepat berubah (volatile), persaiangan yang ketat, persisten, dan kompleks. Kenaikan harga properti disebabkan karena harga tanah yang cenderung naik, dan supply tanah bersifat tetap sedangkan demand nya akan selalu bertambah besar seiring dengan pertambahan jumlah penduduk serta bertambahnya kebutuhan manusia akan tempat tinggal, perkantoran, pusat perbelanjaan, taman hiburan dan lain-lain. Sudah selayaknya apabila perusahaan pengembang mendapatkan keuntungan yang besar dari kenaikan harga properti tersebut, dan dengan keuntungan yang diperolehnya maka perusahaan pengembang dapat memperbaiki kinerja keuangannya sehingga dapat menaikkan harga saham. 


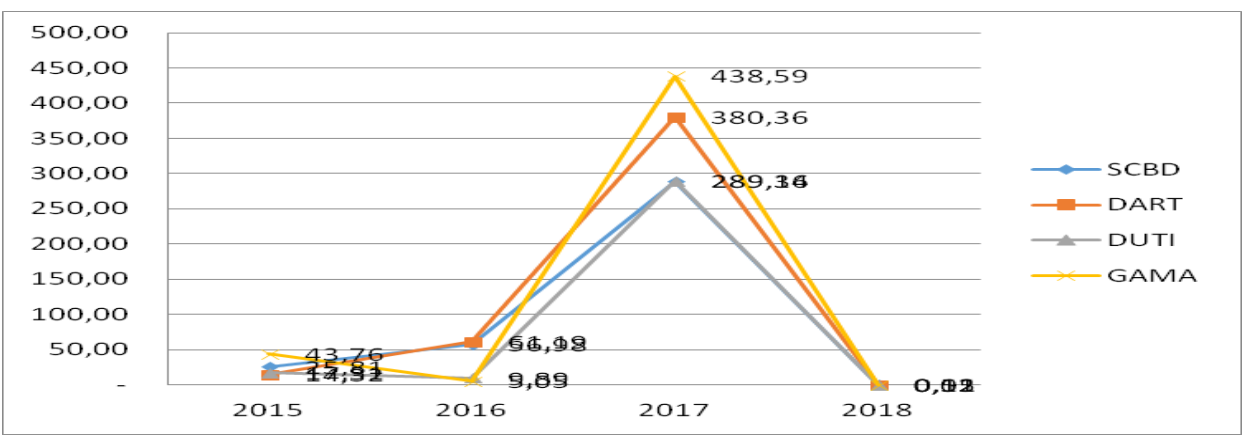

Dari grafik tersebut dapat dilihat bahwa secara keseluruhan, pergerakan return saham properti dan real estate dari tahun 2015 hingga tahun 2018 mengalami fluktuatif. EPS properti dan real estate mencapai puncak tertinggi pada tahun 2017 sebesar 438,59 dan pada tahun 2018 mencapai puncak terendah, yaitu 0.15. Dari grafik tersebut bisa disimpulkan bahwa EPS bisa mengalami kenaikan atau bahkan penurunan yang drastis.

Berbanding terbalik dengan penuruan drastis EPS pada tahun 2015. Rendahnya pertumbuhan properti membuat indeks harga saham sektor ini turun sehingga laba per lembar saham ikut menurun. Awal tahun 2015 indeks saham properti pada Bursa Efek Indonesia berada pada level 0.02. Kinerja sektor properti yang kurang baik membuat indeks sahamnya pun turun, bahkan mencapai 496.9.

Sepanjang tahun 2016 ternyata saham sektor properti masih belum pulih. Indeks sektor properti hanya naik sekitar 6 persen. Kenaikan ini tidak sebanding dengan Indeks Harga Saham Gabungan (IHSG) yang melesat 16.1 persen dalam periode yang sama. Data Bank Indonesia juga menunjukan kredit sektor properti hingga November 2016 juga hanya naik 7 - 9 persen. Padahal Pemerintah telah melonggarkan aturan agar permintaan terhadap properti kembali meningkat. (Online), tersedia: www.bareksa.com (30 Desember 2016).

Selain itu, rendahnya daya beli masyarakat juga diindikasi sebagai penyebab menurunnya return saham perusahaan properti. Hal ini terbukti dari survei yang dilakukan Bank Indonesia (BI). Survei bank sentral terkait Indeks Keyakinan Konsumen (IKK) Juni 2017 sebesar 122.4 atau turun 3.5 poin jika dibandingkan dengan IKK pada bulan sebelumnya. Lemahnya kemampuan beli masyarakat ini membuat investasi properti tidak bergerak. Dengan kata lain, banyak investor yang tidak dapat menjual aset propertinya dengan harga yang lebih tinggi dari posisi beli. (Online), tersedia: www.cnnindonesia.com (17 Juli 2017).

Melihat fakta bahwa tidak ada kepastian mengenai EPS yang akan didapatkan oleh investor ketika melakukan investasi saham, tentu seorang manajemen akan berupaya melakukan tidakan agar nilai sahamnya diperusahaannya terlihat baik. Adapun salah satunya dengan cara melakukan tindakan yang biasa disebut manajemen laba. oleh karena itu, perlu diketahui faktor-faktor yang mempengaruhi Manajemen Laba dalam keuangan.

Manajemen laba didefinisikan sebagai upaya manajer perusahaan untuk mengintervensi atau mempengaruhi informasi dalam laporan keuangan dengan tujuan untuk mengelabui stakeholder yang ingin mengetahui kinerja keuangan (Sulistyanto, 2008). Manajemen laba dapat dikatakan sebagai permainan akuntansi. Apalagi jika melihat bahwa rekayasa tersebut merupakan upaya untuk menyembunyikan dan mengubah informasi dengan mempermainkan besar kecilnya angka-angka komponen laporan keuangan yang dilakukan ketika mencatat dan menyusun informasi. Hal tersebut akan menimbulkan dampak bagi stakeholder, karena tidak dapat memperoleh informasi 
yang valid dan memadai untuk memastikan apa yang seharusnya dilakukan (Sulistyanto, 2008).

Menurut Scott (2011) beberapa motivasi yang mendorong manajemen melakukan earning management, antara lain adalah (1) Motivasi bonus, yaitu manajer akan berusaha mengatur laba bersih agar dapat memaksimalkan bonusnya; (2) Hipotesis perjanjian hutang (Debt Covenant Hypothesis), berkaitan dengan persyaratan per-janjian hutang yang harus dipenuhi, laba yang tinggi diharapkan dapat mengurangi kemungkinan terjadinya pelanggaran syarat perjanjian hutang; (3) Meet Investors Earnings Expectations and Maintain Reputation, perusahaan yang me-laporkan laba lebih besar daripada ekspektasi investor harga sahamnya akan mengalami pening-katan yang signifikan karena investor mempre-diksi perusahaan akan mempunyai masa depan yang lebih baik; (4) IPO (Initial Public Offering), manajer perusahaan yang akan go public ter-motivasi untuk melakukan manajemen laba sehingga laba yang dilaporkan menjadi tinggi dengan harapan dapat menaikkan harga saham perusahaan.

\section{TINJAUAN PUSTAKA}

\section{Hipotesis Penelitian}

Pengaruh Return on Equity (ROE) terhadap Manajemen Laba

Return On Equity (ROE) yang semakin meningkat belum tentu menggambarkan tingkat keefisienan manajemen perusahaan secara nyata dalam mengelola modal perusahaan yang di investasikan oleh para investor. Karena dengan memunculkan laba yang besar didalam laporan keuangan akan mempengaruhi tingkat kepercayaan investor. Sehingga Hal ini menyebabkan permintaan pasar permintaan pasar (investor) untuk melakukan investasi dalam perusahaan semakin tinggi. Permintaan pasar yang tinggi dapat mengakibatkan nilai Harga Saham perusahaan tersebut akan meningkat.

\section{$\mathrm{H}_{1}$ : Return on Equitty berpengaruh terhadap Manajemen Laba}

\section{Pengaruh Earning Per Share (EPS) terhadap Manajemen Laba}

Perusahaan yang mempunyai Earning Per Share (EPS) rendah berakibat menurunnya target pencapaian perusahaan dalam menghasilkan laba yang lebih banyak yang nantinya akan dibagikan kepada investor. diduga hal tersebut akan mengancam manajemen yang menjabat sekarang, sehingga manajemen terdesak untuk melakukan praktek manajemen laba karena perusahaan terancam tidak bisa memenuhi kewajiban dalam pembagian deviden kepada owner dan juga, selain itu para investor tidak akan menanamkan uangnya diperusahaan tersebut.

\section{$\mathbf{H}_{2}$ : Earning Per Share berpengaruh terhadap Manajemen Laba}

\section{Pengaruh Debt to Equity Ratio (DER) terhadap Manajemen Laba}

Penelitian Agustia (2013) menyatakan bahwa Leverage yang diproksikan oleh Debt to Equity Ratio (DER) berpengaruh Positif dan signifikan terhadap Manajemen Laba. Sejalan dengan hasil penelitian tersebut Guna \& Herawaty (2010) menyatakan bahwa Leverage yang diproksikan oleh Debt to Equity Ratio (DER) berpengaruh Positif dan signifikan terhadap Manajemen Laba. Kedua hasil penelitian tersebut diperkuat hasil penelitian yang dilakukan oleh Agustia, \& Suryani, (2018). menyatakan bahwa Leverage yang diproksikan oleh Debt to Equity Ratio (DER) berpengaruh Positif dan signifikan terhadap Manajemen Laba.

\section{$\mathrm{H}_{3}$ : Debt to Equity Ratio berpengaruh terhadap Manajemen Laba}




\section{Pengaruh Price Earning Ratio (PER) terhadap Manajemen Laba}

Rasio ini diperhatikan oleh pemodal/investor, memilih PER yang rendah menunjukkan nilai pasar yang tinggi atas saham karena semakin murah saham tersebut untuk dibeli dan semakin baik pula kinerja per lembar saham dalam menghasilkan laba bagi manajemen perusahaan. Semakin baik kinerja per lembar saham akan mempengaruhi tingkat kepercayaan pemilik atas pencapaian yang telah dilakukan manajemen. Masa jabatannya akan diperpanjang serta di ikuti oleh kenaikan gajinya. Maka dari itu manejemen akan selalu berupaya melakukan tindakan manajemen laba agar banyak investor membeli saham perusahaan tersebut, sehingga saham tersebut akan menjadi naik dan diminati oleh investor lain dan pada akhirnya akan menaikkan pula harga sahamnya.

\section{H4: Price Earning Ratio berpengaruh terhadap Manajemen Laba}

\section{Pengaruh Net Profit Margin (NPM) Terhadap Manajemen Laba}

Net Profit Margin (NPM) yang tinggi memberikan sinyal akan keberhasilan perusahaan dalam mengembang misi dari pemiliknya. Namun perusahaan yang tidak mampu menghasilkan keuntungan akan mempengaruhi investor maupun calon investor untuk tidak melakukan investasi. Investor akan bersedia membeli saham dengan harga lebih tinggi apabila memperkirakan tingkat Net Profit Margin (NPM) perusahaan tinggi, dan sebaliknya investor tidak bersedia membeli saham dengan harga tinggi apabila nilai Net Profit Margin (NPM) perusahaan rendah. Dalam situasi Net Profit Margin (NPM) perusahaan yang rendah akan menyebabkan manajemen untuk melakukan praktek manajemen laba, dengan harapan investor akan menanamkan saham di perusahaan tersebut sehingga return perusahaan tersebut akan meningkat pula.

\section{$H_{5}$ : Net Profit Margin berpengaruh terhadap Manajemen Laba}

\section{METODE PENELITIAN}

Populasi dan Sampel

Populasi dalam penelitian ini adalah perusahaan Property dan Real Estate yang terdaftar pada Bursa Efek Indonesia (BEI) selama periode 2016-2018. Kriteria yang digunakan untuk memilih sampel adalah sebagai berikut, Perusahaan Property dan Real Estate yang terdaftar di BEI. Perusahaan mempublikasikan laporan keuangan dengan lengkap dan Laporan keuangan tahunan yang diterbitkan menggunakan nilai mata uang rupiah $(\mathrm{Rp})$

\section{Variabel dependen \\ Manajemen Laba (Y)}

Penghitungan manajemen laba pada penelitian ini menggunakan model jones dimodifikasi (modified jones model). Rumus yang digunakan untuk menghitung manajemen laba dengan metode discretionary accruals. Perhitungan Manajemen Laba menggunakan rumus sebagai berikut:
(1) TACit $=$ Nit - CFOit
(2) $\quad$ TCAitAit $-1=\beta 1(1$ Ait -1$)+\beta 2(\triangle$ REVitAit -1$)+\beta 3($ PPEitAit -1$)+$ eit
(3) $N D A C i,=\beta 1(1$ Ait -1$)+\beta 2(\triangle$ REVit $-\triangle$ RECitT Ait -1$)+\beta 3($ PPEitAit -1$)$
(4) DACit $=[$ TACAit $-1 /]-N D A C i, t$ 


\section{Variabel Independen \\ Return on Equity $\left(\mathbf{X}_{1}\right)$}

Profitabilitas merupakan rasio yang bertujuan untuk mengetahui kemampuan perusahaan dalam menghasilkan suatu laba baik dalam hubungannya dengan penjualan, aset maupun modal saham tertentu selama periode waktu tertentu dan juga memberikan gambaran tentang tingkat efektifitas manajemen dalam melaksanakan kegiatan operasinya. Efektifitas disini diliat dari laba yang dihasilkan terhadap penjualan dan modal saham.

Penelitian ini menggunakan metode analisis rasio profitabilitas karena masyarakat pada umumnya, berpandangan bahwa pengukuran tingkat keberhasilan operasional dan efektivitas perusahaan didasarkan pada tingkat profitabilitas yang dicapai perusahaan, profitabilitas diukur dengan return on equity (ROE).

\section{ROE $=\underline{\text { Net Profit }}$ \\ Ekuitas}

\section{Earning Per Share $\left(\mathbf{X}_{2}\right)$}

Kenaikan earning per share berarti perusahaan sedang dalam tahap pertumbuhan atau kondisi keuangannya sedang mengalami peningkatan dalam penjualan dan laba, atau dengan kata lain semakin besar earning per share menandakan kemampuan perusahaan dalam menghasilkan keuntungan bersih setiap lembar saham. (Suherman et al, 2016). Perhitungan earning per share (EPS) menggunakan rumus sebagai berikut:

$$
\text { EPS }=\frac{\text { Laba Bersih Setelah Pajak }}{\text { Jumlah Lembar Saham yang beredar }}
$$

\section{Debt to Equity Ratio $\left(\mathbf{X}_{3}\right)$}

Solvabilitas adalah kemampuan suatu perusahaan untuk memenuhi segala kewajiban finansialnya pada saat perusahaan tersebut dilikuidasi. Solvabilitas diukur dengan menggunakan debt to equity ratio. Debt to equity ratio adalah rasio yang digunakan untuk menentukan seberapa besar hutang perusahaan yang dibiayai oleh ekuitas. Semakin besar debt to equity ratio menunjukkan kondisi perusahaan yang kurang sehat karena sebagian besar ekuitas yang dimiliki telah digunakan untuk membiayai hutang perusahaan.

\section{Debt to Equity ratio= Total Hutang}

Tota Ekuitas

\section{Price Earning Ratio $\left(\mathbf{X}_{4}\right)$}

PER merupakan rasio yang menggambarkan apresiasi pasar terhadap kemampuan perusahaan dalam mengahsilkan laba. Rasio ini mengindikasikan derajat 
kepercayaan investor pada kinerja masa depan perusahaan. Rumus perhitungan PER adalah sebagai berikut:

Price Earning Ratio = $\quad$ Harga Saham yang beredar

Laba Per Lembar Saham

\section{Net Profit Margin $\left(\mathbf{X}_{5}\right)$}

Hubungan antara laba bersih sesudah pajak dan penjualan bersih menunjukkan kemampuan manajemen dalam mengemudikan perusahaan secara cukup berhasil untuk menyisakan margin tertentu sebagai kompensasi yang wajar bagi pemilik yang telah menyediakan modalnya untuk suatu resiko. Hasil dari perhitungan mencerminkan keuntungan netto per rupiah penjualan. Para investor pasar modal perlu mengetahui kemampuan perusahaan untuk menghasilkan laba.. Perhitungan net profit margin (NPM) menggunakan rumus sebagai berikut:

$$
\text { Net Profit Margin }(N P M)=\frac{\text { Laba Bersih Setelah Pajak }}{\text { Penjulan }}
$$

\section{HASIL DAN PEMBAHASAN}

Hasil Analisis Statistik Deskriptif

\begin{tabular}{|l|c|c|c|c|c|}
\hline & MJ & ROE & EPS & DER & PER \\
\hline Mean & -0.788667 & 7.800000 & 47.62578 & 0.448889 & 40.19533 \\
\hline Median & -0.290000 & 5.250000 & 12.57000 & 0.450000 & 13.82000 \\
\hline Maximum & 6.190000 & 38.55000 & 438.5900 & 1.070000 & 411.3400 \\
\hline Minimum & -19.75000 & -6.940000 & -19.10000 & 0.070000 & -11.07000 \\
\hline Std. Dev. & 3.297459 & 8.598990 & 97.35825 & 0.243303 & 78.29352 \\
\hline Skewness & -4.304625 & 1.647671 & 2.932350 & 0.464577 & 3.327410 \\
\hline Kurtosis & 26.14529 & 6.279017 & 10.60863 & 2.642017 & 14.50364 \\
\hline & & & & & \\
\hline Jarque-Bera & 1143.419 & 40.52105 & 173.0362 & 1.859022 & 331.1634 \\
\hline Probability & 0.000000 & 0.000000 & 0.000000 & 0.394747 & 0.000000 \\
\hline & & & & & \\
\hline Sum & -35.49000 & 351.0000 & 2143.160 & 20.20000 & 1808.790 \\
\hline Sum Sq. Dev. & 478.4225 & 3253.476 & 417059.7 & 2.604644 & 269714.5 \\
\hline & & & & & \\
\hline Observations & 45 & 45 & 45 & 45 & 45 \\
\hline
\end{tabular}

a. Berdasarkan tabel diatas dapat dideskripsikan bahwa Manajemen Laba sebagai variabel dependen (y) memiliki nilai terendah $-19,75$ dan nilai tertinggi 6,19 nilai rata- rata (mean) sebesar $-0,788$ dengan standar deviasi sebesar 3,297. Nilai mean sebesar -

-0,788 (7,88\%) menunjukkan bahwa rata-rata Manajemen Laba perusahaanperusahaan sampel yang diteliti adalah sebesar 7,88\% dari total Manajemen Laba. 
Standar deviasi sebesar 32,97\% menunjukkan bahwa Manajemen Laba dari perusahaan-perusahaan sampel yang diteliti memiliki perbedaan yang relative tinggi.

b. Variabel Return on Equity $\left(\mathrm{X}_{1}\right)$ memiliki nilai minimum -6,940 dan nilai maksimum 38.550 nilai mean sebesar 7,800 dan standar deviasi sebesar 8,59, hal ini menunjukkan bahwa $85,9 \%$ rata-rata Return on Equity. Standar deviasi sebesar $85,9 \%$ menunjukkan total profitabilitas dari perusahaan-perusahaan sampel yang diteliti memiliki perbedaan yang relatif tinggi.

c. Variabel Earning Per Share $\left(\mathrm{X}_{2}\right)$ memiliki nilai minimum -19,10 dan nilai maksimum 438,59, nilai mean sebesar 43,889 dan standar deviasi sebesar 97,358. Hal ini menunjukkan bahwa 97,5\% rata rata Earning Per Share. Standar deviasi sebesar 97, 3\% menunjukkan Earning Per Share dari perusahaan - perusahaan sampel yang diteliti memiliki perbedaan yang relatif tinggi.

d. Variabel Debt to Equity Ratio $\left(\mathrm{X}_{3}\right)$ memiliki nilai minimum 0,070 dan nilai maksimum 1,070, nilai mean sebesar 0,448 dan standar deviasi sebesar 0,243. Hal ini menunjukkan bahwa rata-rata Debt to Equity Ratio sebesar 2,43\% dari perusahaan- perusahaan yang dijadikan sampel penelitian. Standar deviasi sebesar 2,43\% menunjukkan Debt to Equity Ratio pada perusahaan-perusahaan sampel yang diteliti memiliki perbedaan relatif rendah.

e. Variabel Price Earning Ratio $\left(\mathrm{X}_{4}\right)$ memiliki nilai minimum -11,07 dan nilai maksimum 411,340, nilai mean sebesar 40,195 dan standar deviasi sebesar 78,293. Hal ini menunjukkan bahwa rata-rata Price Earning Ratio sebesar 40,19\% dari perusahaan-perusahaan yang dijadikan sampel penelitian. Standar deviasi sebesar 78,29\% menunjukkan Price Earning Ratio pada perusahaan-perusahaan sampel yang diteliti memiliki perbedaan yang relatif tinggi.

\section{Estimasi Regresi Data Panel}

\section{Random Effect Model}

Dependent Variable: MJ

Method: Panel EGLS (Cross-section random effects)

Date: 10/06/19 Time: 19:39

Sample: 20162018

Periods included: 3

Cross-sections included: 15

Total panel (balanced) observations: 45

Swamy and Arora estimator of component variances

\begin{tabular}{crrrl}
\hline Variable & Coefficient & Std. Error & t-Statistic & Prob. \\
\hline C & 0.628082 & 1.694388 & 0.370684 & 0.7129 \\
ROE & -0.195256 & 0.057863 & -3.374442 & 0.0017 \\
EPS & 0.010306 & 0.005921 & 1.740492 & 0.0897 \\
DER & 1.724147 & 2.611026 & 0.660333 & 0.5129 \\
PER & -0.000256 & 0.005050 & -0.050675 & 0.9598 \\
NPM & -2.854752 & 1.427727 & -1.999508 & 0.0526 \\
\hline
\end{tabular}

Effects Specification

S.D. Rho 
Cross-section random

$2.823078 \quad 0.7915$

Idiosyncratic random

$1.449049 \quad 0.2085$

\begin{tabular}{lllr}
\hline \multicolumn{4}{l}{ Weighted Statistics } \\
\hline \hline R-squared & 0.564600 & Mean dependent var & -0.224086 \\
Adjusted R-squared & 0.508779 & S.D. dependent var & 2.074294 \\
S.E. of regression & 1.453813 & Sum squared resid & 82.42932 \\
F-statistic & 10.11455 & Durbin-Watson stat & 1.660838 \\
Prob(F-statistic) & 0.000003 & & \\
\hline \hline
\end{tabular}

Unweighted Statistics

\begin{tabular}{lclc}
\hline \hline R-squared & 0.243228 & Mean dependent var & -0.788667 \\
Sum squared resid & 362.0569 & Durbin-Watson stat & 0.378122 \\
\hline
\end{tabular}

Sumber: Hasil Olahan Eviews 9.0, 2019

\section{Pemilihan Model Estimasi Model}

Kesimpulan Model

\begin{tabular}{|c|l|l|c|}
\hline No. & \multicolumn{1}{|c|}{ Metode } & \multicolumn{1}{|c|}{ Pengujian } & Hasil \\
\hline 1 & Uji Chow & CEM vs FEM & FEM \\
\hline 2 & Uji Hausman & REM vs FEM & FEM \\
\hline 3 & Uji Langrange Multiplier & CEM vs REM & REM \\
\hline
\end{tabular}

Berdasarkan hasil pengujian yang sudah dilakukan diketahui bahwa pada uji chow terpilih model FEM dengan nilai cross-section $f$ sebesar 0.000 lebih kecil dari 0,05 dan pada uji hausman model yang terpilih adalah estimasi model REM dengan nilai cross section random sebesar 0.3853 lebih besar dari 0,05. Lalu, pada uji Lagrange Multiplier model yang terpilih adalah estimasi model CEM dengan nilai Breusch-Pagan sebesar 0.000 lebih kecil dari 0,05. Maka dapat ditarik kesimpulan bahwa model estimasi yang akan digunakan dalam penelitian ini adalah model Random Effect Model (REM).

\section{Uji Hipotesis}

\section{Uji Adjusted $\mathbf{R}^{2}$ (Koefisien determinasi)}

$$
\begin{array}{|l|l}
\hline \text { Adjusted R-squared } & 0.508779
\end{array}
$$

Hasil Adjusted R-Squared pada model ini adalah 0.508779 artinya bahwa variasi perubahan naik turunnya Manajemen Laba dapat dijelaskan oleh Return on Equity, Earning Per Share, Debt to Equity Ratio, Price Earning Ratio dan Net Profit Margin sebesar $50.87 \%$, sedangkan sisanya $49.13 \%$ disebabkan oleh variabel atau hal lain diluar dari variabel yg diteliti.

\section{Uji t Parsial}

\begin{tabular}{crrrr}
\hline \hline Variable & Coefficient & Std. Error & t-Statistic & Prob. \\
\hline C & 0.628082 & 1.694388 & 0.370684 & 0.7129 \\
ROE & -0.195256 & 0.057863 & -3.374442 & 0.0017
\end{tabular}




\begin{tabular}{lrrrr} 
EPS & 0.010306 & 0.005921 & 1.740492 & 0.0897 \\
DER & 1.724147 & 2.611026 & 0.660333 & 0.5129 \\
PER & -0.000256 & 0.005050 & -0.050675 & 0.9598 \\
NPM & -2.854752 & 1.427727 & -1.999508 & 0.0526 \\
\hline
\end{tabular}

Berdasarkan hasil uji t pada analisis resgresi panel menunjukan, maka dapat disimpulkan hasil hipotesis sebagai berikut:

1. Pengujian hipotesis pertama $\left(\mathrm{H}_{1}\right)$

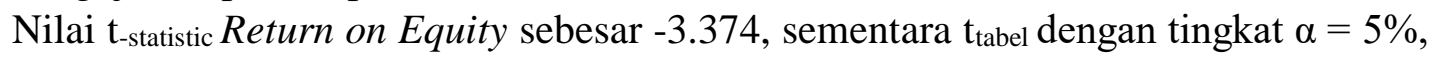
df $(n-k)=45-5$ didapat nilai tabel sebesar 1.683. Dengan demikian t-statistic Return on Equity (-3.374) < t tabel (-1.683) dan nilai Prob. 0,0017 < 0,05 maka dapat disimpulkan bahwa variabel Return on Equity dalam penelitian ini memiliki pengaruh terhadap Manajemen Laba. Return on Equity mempunyai koefisien regresi kearah negatif sebesar 3,374 (33,74\%). Hal ini berarti semakin rendah nilai Return on Equity perusahaan, maka Manajemen Laba akan semakin tinggi.

2. Pengujian hipotesis kedua $\left(\mathrm{H}_{2}\right)$

Nilai t-statistik Earning Per Share sebesar 1.740 sementara tabel dengan tingkat $\alpha=$ $5 \%$, df $(\mathrm{n}-\mathrm{k})=45-5$ didapat nilai $\mathrm{t}_{\text {tabel }}$ sebesar 1.683. Dengan demikian $\mathrm{t}_{\text {-statistic }}$ Earning Per Share (1.744) < $\mathrm{t}_{\text {tabel }}(1.683)$ dan nilai Prob. $0.0897>0,05$ maka dapat disimpulkan bahwa variabel Earning Per Share dalam penelitian ini tidak memiliki pengaruh terhadap Manajemen Laba. Earning Per Share mempunyai koefisien regresi kearah positif sebesar $1,744(17,44 \%)$. Hal ini berarti semakin tinggi nilai Earning Per Share suatu perusahaan maka Nilai Manajemen Laba akan semakin rendah.

3. Pengujian hipotesis ketiga $\left(\mathrm{H}_{3}\right)$

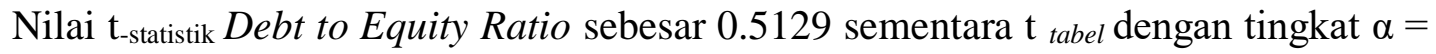
$5 \%$, df $(\mathrm{n}-\mathrm{k})=45-5$ didapat nilai $\mathrm{t}_{\text {tabel }}$ sebesar 1,683. Dengan demikian $\mathrm{t}_{\text {-statistic }}$ Debt to Equity Ratio $(0,660)<\mathrm{t}$ tabel $(1,894)$ dan nilai Prob. 0,5129 > 0,05 maka dapat disimpulkan bahwa variabel Debt to Equity Ratio dalam penelitian ini tidak memiliki pengaruh terhadap Manajemen Laba. Debt to Equity Ratio mempunyai koefisien regresi kearah Positif sebesar 0,660 (66,0\%). Hal ini berarti semakin rendah tinggi Debt to Equity Ratio suatu perusahaan maka Nilai Manajemen Laba akan semakin rendah.

4. Pengujian hipotesis keempat $\left(\mathrm{H}_{4}\right)$

Nilai t-statistik Price Earning Ratio sebesar -0.050 sementara $t_{\text {tabel }}$ dengan tingkat $\alpha=$ $5 \%$, df $(n-k)=45-5$ didapat nilai $t_{\text {tabel }}$ sebesar 1,683. Dengan demikian $\mathrm{t}_{\text {-statistic }}(-$ $0.050)>\mathrm{t}$ tabel $(-1,683)$ dan nilai Prob. 0,9598 > 0,05 maka dapat disimpulkan bahwa variabel Price Earning Ratio dalam penelitian ini tidak memiliki pengaruh terhadap Manajemen Laba. Price Earning Ratio mempunyai koefisien regresi kearah Negatif sebesar 0,050 (5,0\%). Hal ini berarti semakin rendah nilai Price Earning Ratio suatu perusahaan, maka Nilai Manajemen Laba akan semakin tinggi.

5. Pengujian hipotesis keempat $\left(\mathrm{H}_{4}\right)$

Nilai t-statistik Net Profit Margin sebesar -1.999 sementara tabel dengan tingkat $\alpha=$ $5 \%$, df $(n-k)=45-5$ didapat nilai $\mathrm{t}_{\text {tabel }}$ sebesar 1,683. Dengan demikian $\mathrm{t}_{\text {-statistic }}(-$ 
$1,999)<\mathrm{t}$ tabel $(-1,683)$ dan nilai Prob. 0,526 < 0,05 maka dapat disimpulkan bahwa variabel Net Profit Margin dalam penelitian ini tidak memiliki pengaruh terhadap Manajemen Laba.. Net Profit Margin mempunyai koefisien regresi kearah negatif sebesar 1,999 (19,99\%). Hal ini berarti semakin rendah nilai Net Profit Margin suatu perusahaan, maka Nilai Manajemen Laba akan semakin tinggi.

\section{KESIMPULAN}

Hasil Penelitian dari pengujian ini menghasilkan bahwa Variabel Debt to Equity Ratio secara parsial berpengaruh terhadap Manajemen Laba. Sedangkan variabel Return on equity, Earning Per Share, Price Earning Ratio dan Net Profit Margin tidak memiliki pengaruh terhadap Manajemen Laba.

\section{DAFTAR PUSTAKA}

Scott, William R. (2011). Financial Accounting Theory. Sixth Edition. Canada: Person Prentice Hall

Guna, Welvin I dan Arleen Herawaty. 2010. Pengaruh Mekanisme Good Corporate Governance, Independensi Auditor, Kualitas Audit Dan Faktor Lainnya Terhadap Manajemen Laba. Jurnal Bisnis Dan Akuntansi Vol. 12, No. 1, April 2010, Hlm. $53-68$.

Agustia, Yofi P., Suryani, Elly. (2018). Pengaruh Ukuran Perusahaan, Umur Perusahaan, Leverage, dan Profitabilitas Terhadap Manajemen Laba (Studi Pada Perusahaan Pertambangan yang Terdaftar di Bursa Efek Indonesia Periode 2014-2016). EJournal Akuntansi Riset. Program Studi Akuntansi. Fakultas Pendidikan Ekonomi dan Bisnis. Universitas Pendidikan Indonesia, 10(1), Retrivied from ejournal.upi.edu/index.php/aset/artikel/view/12571

Agustia, dian. 2013. Pengaruh Faktor Good Corporate Governance, Free Cash Flow, dan Leverage Terhadap Manajemen Laba. Jurnal Akuntansi dan Keuangan, Vol. 15, No. 1, Mei 2013, 27-42 DOI: 10.9744/jak.15.1.27-42 ISSN 1411-0288 print / ISSN 2338-8137 online

http://www.datacon.co.id/Outlook-2012Fokus.html.Indonesian Comercial News Letter.

Diakses tanggal 11 Agustus 2016.

http://www.idx.co.id. Diakses tanggal 9 Juni 2016.

http://www.sahamok.com/emiten/kapitaliasi-pasar. Diakses tanggal 21 Juni 2016.

https://market.bisnis.com/read/20180620/191/807909/ihsg-tertekan-waspadai-sahamyang-sensitif-suku-bunga 